Article

\title{
Playful Machines and Heritage: How to Prepare Future Cultural Histories?
}

\author{
Mirosław Filiciak (D) \\ Department of Cultural Studies, SWPS University of Social Sciences and Humanities, 03-815 Warsaw, Poland; \\ mfiliciak@swps.edu.pl
}

Received: 24 March 2020; Accepted: 7 July 2020; Published: 20 July 2020

\begin{abstract}
How are we to tackle digital heritage? The fact that its code can be copied, combined with a strong reliance on user interaction, is a distinguishing characteristic of digital art, one which also complicates framing it with the traditional categories of art history. Therefore, in my search for the new ways to preserve heritage, appropriate for digital objects, I will use a case study where technical and social elements play an important role and where we can already speak of a partly institutionalized network aimed at preservation, even if its identification within the field of art, or heritage, is not exactly obvious. I propose an analysis based on the research of the Polish community of pinball machine collectors. My case study will also address the question of the category of locality with regard to projects featuring seemingly universal digital elements. Reflecting on the strategies that the pinball community uses to preserve its artifacts and to animate social activity centered upon those artifacts, can help facilitate modeling at least some practices needed to preserve digital art, practices more inclusive than the traditional approaches, and uniting, even if imperfectly, rather than dividing various social groups.
\end{abstract}

Keywords: digital art; game studies; media archaeology; pinball machines; museology

This article outlines a possible way to think, create, share and preserve cultural histories, based on the observations drawn from a recent research project. I will use a case study of real social practices as a point of reference for a reflection on the possible shape of future GLAM institutions (galleries, libraries, archives and museums) debated today both within the cultural studies and the heritage institutions. Notably, this text approaches cultural history not as a field whose boundaries are imposed and regulated by the academic or institutional discourse but as a social practice, including commodified market practice. Consequently, what constitutes heritage is not decided exclusively by the experts but also by the "common" people, mostly non-professional enthusiasts of a particular subject, and by the market responding to a social demand. My article focuses on the interfaces between these perspectives, though it outlines potential areas of conflict and tension.

My proposals will be framed by the context of an actually existing museum: I am going to discuss the processes manifest in the ways it functions and speculate about the role it could fulfill as a mediator in the dialogue between the fan community and the critical academic reflection. It will serve as an illustration of actual dilemmas facing the practitioners and theoreticians of culture, especially digital culture, and as an example of possible and constructive ways of overcoming those dilemmas.

\section{A Basement in Cracow}

We are in Cracow, one of Poland's oldest cities and its former capital, traditionally considered one of the country's key cultural centers. It is also seen as a conservative city, more than politically: a significant number of Cracow's museums houses collections that are centuries years old, often as old as medieval, and consist largely of religious art. Historically, they were shaped by the Polish noble 
class, and in modernity, after the country regained independence in 1918, mostly by the intelligentsia which, for the most part, had aristocratic roots.

But the museum I am visiting is located not in a distinguished edifice but in a basement whose entrance can be reached through the backyard of a tenement building. In its bar-like interior I meet the founder. Our conversation is interrupted by the visitors: mostly middle-aged men, but during the two hours I spend inside I get to see a clientele diversified in terms of both age and gender. A young Ukrainian couple asks if they can leave their shopping with us: large paper bags with logos of clothing companies. A large Muslim family negotiates who is going to help the mother resting with an infant in an armchair by the entrance and who gets to come inside. Some are here clearly by accident, others ask detailed questions about the location of particular pieces and share the details of the long-planned visit, an integral part of their Cracow trip. I am not surprised by the volume of visitors, after all, it is summer, middle of the tourist season, and the facility is located in Kazimierz, Cracow's former Jewish district and a mandatory element of the tourist routes. What strikes me is the strong emotional response to the place. My conversation with the owner is interrupted not only by the selling of tickets, but also by the guests leaving the exhibition, often after several hours spent inside, sharing their admiration for the collection, and often, memories evoked by the exhibition. They promise to return one day. When I comment on it, my host proudly points to one of the shelves and shows me artifacts donated by the museum visitors.

My own visit and participatory observation constitute a part of research dedicated to the Polish pinball machines community. It grew out of my other project, employing the perspective of media archeology and focusing on VHS recorders, a different kind of machine imported to Poland during the Communist era and initially used for public screenings rather than home viewing. This local use- beyond the boundaries of the official system of technical support and tape distribution-resulted in the development of a rich culture, which mixed grassroots elements with a unique, peripheral, and often piracy-based entrepreneurship (Filiciak 2018). I have decided to look at how these local practices travel not only in space (along the West-East axis) but also in time (past vs. present). This has produced a series of interviews and participatory observations conducted among the pinball community-I have selected the respondents using the snowball method, following the recommendations of the already interviewed participants. I have talked to two owners of flipper arcades but also to private collectors, people involved in machine maintenance, administrators of the Polish flipper forum and the organizers of the flipper competitions (having taken part in one event as a player), finally-I talked to the fans. The boundaries between these categories can be fluid and I cannot provide an exact number of conducted interviews: less than a dozen were pre-arranged but I have conducted about the same number in the less formal conditions of the competition. There were also instances of listeners joining in the ongoing conversation.

The small size of the flipper community privileges the ethnographic approach in my analyzes but I try to combine it with other methods, aware of the problems related to obtaining quantitative data and combining data collection performed through direct contact and via the Internet (Saukko 2005; Hargittai and Sandvig 2015). This is because my project involves also following global forums and websites, even though I view them-as the majority of my respondents-as a context or a source of information rather than a key element of research. What was crucial for me during the interviews and the observations was the presence of pinball machines, or at least their emulators, functioning as evocative objects, i.e., objects evoking memories, allowing the translation of abstract, theoretical questions to the level of everyday experience-facilitating conversations with strangers as well as observation of their emotional relationships with the machines (Turkle 2007). I also need to mention (this will be of importance later in my argument) that even though I met both men and women of various ages during my visit to the museum, while conducting the interviews with the community animators, I talked mostly to men, usually between the ages of 40 and 50 (with the exception of two slightly younger people who encountered flippers through their older brothers, and one older 
serviceman). Having gotten to know this community, I believe this was not the result of the method used to recruit the respondents, but a representative selection for this group.

The range of employed research methods also includes elements of autoethnography, although I am aware of its risks (Ellis et al. 2011). In the present case, they are mainly related to the problem of nostalgia and the limits it imposes on the critical outlook. However, since nostalgia has a significant impact on the motivations of many of my respondents, my goal is not to annul it but to refit it with critical reflection. I am a forty-something male myself, I come from Cracow, and I remember well my own visits to pinball machine and arcade salons in the 1980s. The discussed museum resembles them a lot, on the aesthetic level. Even though in the 1980s most pinball and arcade machines were installed in barracks and wagons parked somewhere on the fringes of housing estates, venues resembling the museum operated also in the city center, close to the Market Square, in basements such as the one described. The place I used to go to was open to minors (like myself at the time), so it did not sell alcohol, but the location in the basement of a historic tenement house, typical of the city center, resulted in a similar decor. Another similarity lies in the fact that already in the 1980s the machines we used were rather worn out: for economic reasons no one could afford importing brand new devices (a point I will return to later in this essay.)

Naturally, the paragraph describing the visit to the museum contains a rather anecdotal description of the its operations. It is a private property and I never learn the scale of the traffic: when the question is asked, the tone of my host changes and he becomes a little suspicious. Instead, the founder and head of the institution is happy to theorize about its operations and collections. His analyses are performed ad hoc and, typical of a practitioner, lacking in academic discipline and methodology, but it is not what matters for the purpose of this text. I am deeply convinced that the Pinball Museum in Cracow is located at the intersection of not only tourist routes but also several threads apparent in the current debate about the digital heritage. It poses the question of balance between the need to preserve historical artifacts on the one hand and to frame them by contemporary contexts on the other. It encourages reflection on the collection's educational aspects versus its shape as appealing experience. It probes the relations between the experts who legitimize cultural institutions and the fans who cannot be ignored in inclusive archival endeavors. Finally, it raises questions about the material aspect of collections, parts of which also include software.

Pinball machines are a kind of arcade game. The gameplay consists of using flippers to operate one or more metallic balls. The pinball tradition can be traced back at least to the 17th century, when outdoor games, such as outdoor billiards or croquet, began to be played inside the court interiors resulting, among other things, in the creation of bagatelle-a standardized version of the game. But the first electric coin-operated games were born in the 1930s and flippers were introduced a decade later. Notably, modern devices of this type also include a storyline, made possible through the addition of new elements: electronics and digital displays. In fact, if we take a look at the machines from the 1980s we will see how a mechanical medium, limited by its physicality, attempted to tell stories using means similar to those used by the video games, which developed parallelly and had their own limitations, tied to the 8-bit platforms. They counted points, registering the progress of the game, and had looped, repeatable missions. The image-based narratives on the pinball cabinets, meant to stir and direct the players' imagination, echoed the eye-catching images from the packaging of computer games, often quite distant from the actual game graphics consisting of a handful of pixels. They also bring to mind the first home video game console connectable to the TV set-the Magnavox Odyssey from 1972-which did not generate graphics in today's sense. The players could control individual dots on the screen using various methods. The visuals were created by plastic overlays placed on the screen. The console did not have a processor or memory but in many respects it played an important role for the development of the industry-partly because of one of the games included in the set, Table 
Tennis, believed to have inspired the famous Pong. ${ }^{1}$ There is also no doubt that pinballs have set the standards for the business model dominant in the early days of the video games industry, i.e., selling coin operated machines to be placed in public and semi-public spaces. In Racing the Beam, a study of the Atari VCS console-containing a meticulous analysis of the impact of hardware on the game design (as dictated by the paradigm of platform studies) -Nick Montfort and Ian Bogost list several examples of the joint development of pinballs and early games. Arcade video games, which gave birth to home video and computer games, shared with the flippers the common space-of bars and salons-but among the shared features and continuances between these forms, the authors also point to the fact that it was the flippers that enabled the one-player challenge, which later became important for all electronic games, and introduced, in 1976, the presentation of the high score list (Montfort and Bogost 2009, pp. 7, 31, 86).

In the really old pinball models, notes Christopher DeLeon, balls stacked on one another were the marker of the player's mistakes (DeLeon 2014, p. 47). The 1980s computer games used a similar, although reversed concept: the icons in the corner of the player's visual field marked not the lost, but the remaining "lives". Still, the flippers and the video games were largely similar, and it is not by accident that the former were made by Atari (until 1983 when the company got into trouble as a result of the game market crash) or Sega (in the second half of the 1990s)—once key companies in the game industry-while Bally, a well known producer of flippers, sold its own gaming console in the mid 1970s. The Ritchie brothers, stars of pinball design, included in their work electronic games solutions. The display of the Star Trek flipper could be used to play Breakout, a famous console game, and in the 1980s and 90s, flipper creators smuggled into their products video game images or references known as "Easter eggs". Obviously, this parallel development and mutual borrowing were not an entirely smooth symbiosis. Ultimately, having to compete with the video games and facing the domestication of electronic entertainment, the pinball market collapsed in the 1990s, and today remains only a small niche. However, for research into the development of digital games, it still constitutes an important, even if now broken, link in their history.

Pinball machines combine mechanical and digital elements. Consequently, they problematize the question of preserving the digital component on the one hand, but on the other, enforce the realization that the digital is also material (Parikka 2010). The recent, important decade in media archeology stresses the role of the apparatus understood as a technical device but also as the social context it reflects, and at the same time is partly shaped by. The experience of a given medium is strongly related to the broadly understood situation of reception. Commenting on the category of dispositif/apparatus, Foucault notes:

What I'm trying to pick out with this term is, firstly, a thoroughly heterogeneous ensemble consisting of discourses, institutions, architectural forms, regulatory decisions, laws, administrative measures, scientific statements, philosophical, moral and philanthropic propositions-in short, the said as much as the unsaid. Such are the elements of the apparatus. The apparatus itself is the system of relations that can be established between these elements. Secondly, what I am trying to identify in this apparatus is precisely the nature of the connection that can exist between these heterogeneous elements ... Thirdly, I understand by the term 'apparatus' a sort of — shall we say-formation which has as its major function at a given historical moment that of responding to an urgent need. The apparatus thus has a dominant strategic function. (Foucault 1980, p. 194)

The visited flipper museum has retained its technical apparatus, similarly to the the digital games museums which increasingly note its importance. In his excellent book, Raiford Guins connects this to the material turn taking place in humanist reflection, including the one on digital artifacts, and to its

1 https://en.wikipedia.org/wiki/Magnavox_Odyssey (accessed on 26 February 2020). 
practical side by citing the declaration of the California Digital Library's Digital Materiality Research Group stating that "there is a strong argument for preserving the integrity of the original hardware and storage media accessioned with a collection, however generic or unremarkable these might appear" (Guins 2014, p. 16; Kirschenbaum et al. 2009, p. 111). Actions such as these are an element of the discussions about the strategies to preserve digital artifacts but also of the debate about the shape of heritage institutions. I believe this to be the second reason to give more attention to pinball machines. Let us take a closer look at those debates and the questions about other elements of the apparatus that the GLAM institutions can try to reproduce.

\section{You Can Take It to a Carpenter, or GLAM in Transition}

The digital age poses significant challenges for the institutions preserving cultural heritage. Even early media art, anchored in technical media, presents difficulties different from the ones encountered in the past and faced, for instance, by the institutions hosting the works of Nam June Paik. Preservation of such works, while technologically problematic — as well as costly-is nonetheless still determined by the individual character of the objects in question (Hölling 2017). It is a quality which dissipates in the case of digital works that, while at times still platform-tied, are also endlessly multiplied and often reliant on user interaction. The importance of the latter function is perhaps best reflected by the presence of categories such as "interactive art" and "digital communities", or the prizes awarded to internet works during Prix Ars Electronica, the most prestigious competition in the world of digital art. How are we to tackle digital heritage?

The answer is complicated, even more so as it is not just the medium that changed but also the attitude towards heritage, and art itself. Much has been written about the political burden of the museum and the criteria for creating collections-the discussions began with a reflection from the perspective of critical anthropology, poststructuralism and Marxism, which analyze the museum as a tool for colonization and racism, including the ways in which the "authority" of those institutions is constructed (Bennett 1998, p. 156). A similar criticism has been directed also at art museums as tools for building specific narratives (Bal 1996). The tensions in question have been the subject of not only academic disputes (presented in a little more detail further in the text), but also of the discussions held among the practitioners, manifesting, for instance, in the relation to the institution of the museum - treated here, as already mentioned, as one element of the heritage institutions network. Naturally, the museum itself never had a single form, as Anke Te Heesen writes in her already historical study. It has developed in its current shape since the 18th century and already at that time was accompanied by discussions about the need to adjust it to the demands of the contemporary day (Heesen 2012). But while in the past the gradual change concerned, among other things, the figure of the custodian, i.e., the guardian of the collection transforming into a curator who creates various narratives by reconfiguring the connections between the available elements of the collection, today's discussion increasingly concerns a change in the collecting logic itself. One example of such tensions, still unresolved at the time I am writing this essay, can be found in the discussion surrounding the definition of the museum held by ICOM (International Council of Museums) - the largest organization gathering the world's museums. The traditional definition, used for over half a century, defines the museum as a "nonprofit institution" that "acquires, conserves, researches, communicates, and exhibits the tangible and intangible heritage of humanity and its environment for the purposes of education, study, and enjoyment" ${ }^{2}$ An alternative, proposed after extensive consultations, which concluded in July, states the following:

Museums are democratising, inclusive and polyphonic spaces for critical dialogue about the pasts and the futures. Acknowledging and addressing the conflicts and challenges of the present, they hold artefacts and specimens in trust for society, safeguard diverse memories

2 https://icom.museum/en/faq/what-is-icoms-definition-of-a-museum (accessed on 26 February 2020). 
for future generations and guarantee equal rights and equal access to heritage for all people. Museums are not for profit. They are participatory and transparent, and work in active partnership with and for diverse communities to collect, preserve, research, interpret, exhibit, and enhance understandings of the world, aiming to contribute to human dignity and social justice, global equality and planetary wellbeing. ${ }^{3}$

It was rejected as too politicized in the vote held during the 25th ICOM General Conference in Kyoto in September 2019, and directed to be re-consulted. But the signals visible in the proposal, even if the definition itself is deemed too progressive, are symptomatic of a change taking place in thinking about museums, or maybe post-museums, and-more broadly-about heritage. The new definition puts emphasis on a critical dialogue, participation and partnership with communities. It views heritage as an element of social dialogue, a living part of the present. And while it cannot be claimed that such an idea of heritage was unaffected by the digital media which, after all, affect the audiences' expectations and challenge also the traditional forms of collecting and sharing artistic works, and while it is easy to point out the "born digital" initiatives (such as Open GLAM or GLAM Wiki ${ }^{4}$ ) as practical responses to this approach, these cannot be tied to digitization only.

Apart from to the tension between the archived past and the present moment of using the collections, or the dilemma as to what elements of the broadly understood dispositif/apparatus are of key importance from the perspective of heritage, there is an ongoing dispute concerning the selection of collected material and its exclusivity or inclusivity. These issues are reflected in the discussions about the definitions of art which, for the last fifty years or so, have lent strength to the sociological and Marxist proposals in the theoretical reflection on art. They posit that the boundaries between art and other areas of culture echo the division into the elites and the subordinated social groups. This is related to the broad problem of the illusory transparency of presented knowledge that asks no questions about the processes of its construction and, above all, about the perspective from which it is constructed. While the questions of locality, power, and gender, have been the subject of academic reflection for decades, they still remain valid. Similar critical perspectives can be also found in postcolonial studies. This social dimension of popular art, available and useful in the everyday sense, seems to align with the potential of digital art but also with the paradigm of the "expediency of culture", proposed by George Yúdice in his widely cited book (Yúdice 2003). Yúdice discusses the new possibilities to legitimize public spending on cultural institutions by making the latter a part of the process of solving social problems. Naturally, Yúdice is aware of the ambiguity accompanying this transformation, treating it as a result of historical processes: not only a liberation of grassroots activity but also a new, neoliberal agenda and globalization turning culture into yet another kind of resource. Importantly, even if it is an outcome of various entities struggling for agency, used for social, economic or political goals, culture must be performed. Seen from this perspective, heritage is no longer just a resource, locked up safely and preserved in a possibly unchanged physical form. It is an element that must be actively used in dynamically changing social contexts.

How does the Cracow Pinball Museum look from this perspective? Apart from being a place that presents and shares its collection of game machines, it is also a bar where you can get a beer, although - the owner stresses-it is not an essential element of the visit, as admission itself is 40 PLN, the equivalent of five beers. What is crucial, in the context of the already mentioned new expectations towards institutions of this kind, is that the exhibit is entirely "playable": the visitors can use all machines for free- - there are almost forty to choose from, apart from a dozen or so arcade video game machines. Exhibited pieces have a dual status: they constitute authentic pieces of heritage but they are also meant for entertainment. My host believes that this is caused directly by the nature of the medium:

3 https://icom.museum/en/activities/standards-guidelines/museum-definition (accessed on 26 February 2020).

4 See GLAM-Wiki initiative by Wikimedia Foundation, https://en.wikipedia.org/wiki/Wikipedia:GLAM (accessed on 26 February 2020), also: https://openglam.org (accessed on 26 February 2020). 
"Machines are there to be played, just like paintings are there to be looked at. If the machines couldn't be used, it would be as if one wasn't allowed to look at the paintings in an art gallery." It is true, of course, but the situation could be seen in a different context, namely, the already established trend towards experience, noticeable among the museum institutions, aimed to increase their attractiveness for the visitors: an attempt to hold attention, often justified with the narrative about the new generation being unable to experience the space of the exhibition the way it was experienced in the past. ${ }^{5}$ But this particular case is also a part of other discussions, signaled earlier. Therefore, let us put aside the question of whether it should be treated as a part of digital art heritage, focusing on other lessons that this unusual example may contribute to thinking about digital heritage.

Pinball fans are a part of a global community that uses spare parts as well as commercial and non-commercial pinball games emulators. Sharing knowledge, they create fully digital display-based machines but also reconstruct classical devices. They debate the canon and act as curators, run museums and arrange exhibitions. At the same time, they form a lively local community anchored strongly in the devotion to their hobby, including also the appreciation for its aesthetics, and regularly organize, for instance, flipper competitions. It is a community united by the fondness for beer and tinkering, and, arguably the most interestingly, the reconstruction of the way the original Polish pinball parlors used to function, due to the economic context, as locations where problems had to be solved creatively and devices patched and self-assembled.

Of course this "liveliness" of the flippers community has its problematic aspects. Among them is the already signaled ad hoc theorizing, which deepens the divide separating it from the academic discourse-while media archeology increasingly allows the history of mechanical and electronic entertainment to be seen as a network of complex relations, highly determined by the social transformations (Huhtamo and Parikka 2011), fans are prone to create simple linear narratives reminiscent of textbook tales of breakthrough moments effected by individual geniuses or particular technological developments (Suominen 2016). It is also the fans that establish canons: the owner of the discussed museum selects his exhibits based on his personal opinion about individual machines. He agrees that some pieces should not be overlooked but this applies only to a handful of pinballs. Everything else is a matter of his personal taste-regardless of the rankings debated and produced by forums such as the Internet Pinball Database (ipdb.org) which, in the opinion of my interlocutor, easily succumbs to fads and manipulations. This seems to confirm the tendency recognized by other authors who point to a diversity of motivations behind the emergence of fan canons-although we also know that academic standards do not have to be ignored in such decisions, especially as collections classified as supporting academic research could be seen as more prestigious (Navarro-Remesal 2017; deWinter and Kocurek 2017).

Acting in a space that is poorly institutionalized and relatively poorly recognized by the academic discourse, fans do not feel much pressure with regard to the standards of machine maintenance-the pressure they do experience is of an economic nature, translating directly into the common and unquestioned acceptance for whatever means are seen as necessary to simply keep the machines working. Regardless, places such as the already mentioned IPDB.org serve to amass impressive technical documentation to support machine servicing. This knowledge also supports the creation of various constructs emulating old games on the new equipment, a process that takes place independently of the reflection on the preservation of digital art but in many ways follows a similar path. This lends support to the DIY activities within the community, as I was told by one collector of original pinballs, who himself builds machines combining mechanical elements with electronics and, most importantly, replacing the traditional, physical playfield with a large screen: "You can find all the blueprints online, take a peek at what the others have come up with and once you gather individual elements, all of it is uses micro-switches and just clicks together, you just assemble it. Woodwork is a

$5 \quad$ Falk and Dierking's The Museum Experience is historically important for this perspective. See (Falk and Dierking 1992). 
separate subject. For that you'll need proper tools and some workspace but you can simply draw a diagram and take it to a carpenter." This results in the creation of machines combining home-made elements, recovered old parts of the original machines and items manufactured today especially for the market of retro-enthusiasts. But my interviews with the fans have also revealed that their definition of authenticity differs from the traditional, conservational notion, as they are aware of their limitations and simply make do with what they have. Besides, the conservational approach evolves as well, although obviously in a slightly different manner. During the Collaborative Games Histories conference co-organized in Tampere by research institutions and the Finnish Museum of Games, Toni Cavén (who conserves machines for a game museum) posed the question if, for instance, during the restoration of an old cabinet one should remove from the surface the heart scratched out on it with a penknife: the mark removes the object from its original state but at the same time is a witness to the social context of the machine's functioning. Cavén also noted a certain paradox: the unavoidably selective reproduction of history. Under the 1976 legal act, introducing a state monopoly on gambling, a significant number of coin-ops in Finland (including pinballs and arcade video games), were requisitioned and destroyed following a five-year grace period. This means that the devices exhibited in Tampere are not "original" in the sense of being the machines once used by the Fins. In Poland, the situation is even more complex: for economic reasons, pinball machines brought from behind the Iron Curtain, mainly from Germany, had already been ruined and required significant, DIY interventions. New devices were not imported as they were simply too expensive. Are those pinball machines, patched up by the enthusiasts, further removed from the historical heritage because of those interventions, or quite on the contrary?

Few fans can afford original machines: some construct cabinets like the one described by the collector cited earlier, others simply use simulators on their consoles and computers-realizing, obviously, that such a solution is a compromise, a substitute for the desired original machine. But whether they use computers or create advanced pinball emulators in the original or original-resembling casings, the Visual Pinball application remains important. It is a program for designing and operating table physics, initially meant as a commercial product but since 2010 available on free license. It works with PinMAME, or flipper MAME (the original MAME software-Multiple Arcade Machine Emulator-was an emulator created over 20 years ago by an Italian programmer Nicola Salmoria, allowing modern computers to run games designed originally for older, increasingly unavailable machines). PinMAME lets the user run the ROM files with game images from the original machines. Interestingly, these ROMs are often put online by the producers themselves, who rightly view it not as a competition but rather a promotion of their devices, and a chance to preserve them. But many are also created by the fans. As such, there is no doubt that a significant part of these resources, just as in the case of video and computer games, infringe on copyright and could be referred to as "rogue archives", created bottom up but also always accessible and free (de Kosnik 2016).

Commercial entities also operate in this sphere, creating software independent of VisualPinball and PinMAME-my respondents mentioned The Pinball Arcade series as an important contribution, although they criticized it for "greediness". The Pinball Arcade is made by the California FarSight Studios, which entered the electronic flipper market in 2004, with the launch of Pinball Hall of Fame: The Gottlieb Collection (in Europe sold as Gottlieb Pinball Classics, released for the contemporary stationary consoles but also Sony's PSP). The game offered a chance to play the classical machines produced by the famous Gottlieb company. The idea of licensed tables caught on and, in 2008, a new version hit the market, this time dedicated to Williams pinballs. But the fans I have talked to, just as the games history scholars, do not always draw clear boundaries between flippers and video games, especially when it comes to their digital simulations. This is why they play the old flippers meant for various platforms, including the PCs, using also-for instance-GOG.com (Good Old Games), a commercial Polish platform, which, in fact, also acts as a curator of old games. Business activity, including online business activity, in the sphere of heritage is a subject deserving a separate analysis, one that goes beyond the scope of this text, and as such can be only signaled here. One should bear in mind that the activity of commercial entities allows many games, a medium doomed without its community, 
to continue to function quite well. However, as a consequence, narratives created around this part of digital game heritage are biased and subordinated to current business calculations. This is why a counterbalance in the form of amateur enthusiasts seems to be of such importance, even if their activity often balances on the brink of copyright breach.

Reflecting on the strategies that the pinball community uses to preserve its artifacts and to animate social activity centered upon them can help facilitate modeling at least some practices needed to preserve digital art, practices more inclusive than the traditional approaches, and uniting, even if imperfectly, rather than dividing, various social groups. This is crucial also because many digital activities undertaken by public institutions quickly fizzle out-building a community around a top-down initiative is never easy.

\section{3. (Re)Designing Future Histories}

Digital art-but also hybrid artifacts such as pinballs discussed in this article-could benefit from the logic being constructed in terms of designing the future. Rodney Harrison, head researcher in the Heritage Futures project, defines heritage as a kind of futurology. In this approach, the archive is a space that creates the future, determining not only hierarchies (by showing what is worthy and unworthy of being archived) but also — through its categorizations —-ways of thinking about the archived content (Harrison 2015). In this context, the opening question of my essay-how to archive games or, more broadly, artifacts of digital culture-becomes a question about the future. It is a question about their place in culture, acceptable ways of thinking about their role (aesthetic, social, economic, etc.) and about the future of cultural institutions. To be able to leave narrow and rudimentary conceptualizations we must be able to redefine their role and embrace decentralization. Traditional cultural institutions continue to be important but in order to remain effective and efficient they must position themselves as nexuses, moderators and mediators between various entities, from fans through researchers to business. The question of preserving old games must be thus accompanied by another one, namely: are we ready for this change in thinking, especially with regard to the legal and institutional ecosystem, but also simply research practice.

As I have shown, cooperation with the fans can be troublesome. Enthusiasm douses a sense of criticism and promotes a one-sided version of history, convenient for the fans. Although the Pinball Museum is an animated place, an undeniable nexus supporting the establishment and maintenance of relationships through a dynamic community, it also, to a degree, perpetuates the exclusive discourse accompanying games. It is a place created by middle-aged men, very often visited by middle-aged men, sometimes in the company of future middle-aged men. The museum shows them the tradition of a medium they consider important but it does so without a critical commentary. History cannot be censored, however, the way we present it remains important. The spaces that offered access to the pinball machines were not inclusive, neither were the arcade games halls. Commenting on this issue in the Australian context, Dan Golding and Lina van Deventer note:

Although women have always played and made videogames, they often found themselves in heavily masculine environments during the early years. The earliest commercial games, like Pong, were often installed in bars-and even in the 1970s many Australian pubs were gender segregated, with (if women were lucky) 'Ladies' Lounges'. And dedicated game arcades weren't much better. Though they weren't segregated, the long association that pinball machines had with organised crime and general antisocial behaviour meant that they weren't always viewed as safe or appropriate places for young women. (Golding and Deventer 2016, chp. 2)

Thus, there is a risk that communities of this kind will both invigorate and reproduce the hierarchies of, of instance, sexist-oriented white, middle-aged men, privileged enough to enjoy this rather expensive hobby. In the recent years, becoming a part of misogynistic online cultures discussed for instance by 
Angela Nagle, gaming communities have often used their relations for toxic behaviors centered around exclusion, and the phenomenon is wider than the infamous GamerGate (Nagle 2017; Mortensen 2018).

There exist numerous similar threats. The nostalgic tale about the old Polish arcades, which in the times of the Polish People's Republic housed pinballs and video games, does not mention violence and extortion, which were an integral element of that reality. It does not mention gambling-in the mainstream fan narratives the arcades simply disappeared from the Polish landscape for economic reasons. This is only partly true: some of the pinball producers, starting with Williams, shifted focus to another branch of their production-machines made for Las Vegas. This reveals another, less exposed, set of connections within the pinball and the whole game industry, and allows us to state that the slot machine arcades did not disappear from the Polish streets at all. In fact, increasing their social reach, they changed their etiquette and became a meeting place for underclass gambling addicts; today's pinball collectors who are the beneficiaries of the systemic transformation in Poland simply do not visit such places anymore.

The lesson of the pinball community is thus not meant as an uncritical idealization of communal grassroots efforts. However, I am still convinced that using the fan energy is both possible and necessary. How are we to redesign museums such as the one in Cracow to preserve what is valuable about them and introduce the critical element? I believe that by becoming a part of wider circulation and entering open space, fun-oriented and fan-fueled exhibits may acquire new functions, other than the reproduction of the existing order. The moment of "museumization" has the potential to create surprising interactions and new situations around the collections. This has already happened before: discussing the history of arcade games, Rainford Guins shows how machines originally meant for entertainment unexpectedly changed their role by the very fact of entering the discussion about heritage, which had never been designed for them. "These machines were monumental for the new game industry in its salad days, while today their remains are monuments of an expeditiously eroding era of gaming, technology, culture, and (public) social experience" (Guins 2014, p. 108). Guins recalls here Aloise Riegl's concept of an "unintentional monument". The meaning of such monuments is assigned by the contemporary audiences and determined by the changing situation and context-largely independent from the creator's intention. Naturally, we are not talking only about monuments; in his 1903 essay, Riegl notes that any given object can have its function. I believe that museums create this space of possibility. And it is precisely the dynamically changing context, partly independent from the creators' intentions, that offers a chance to go beyond the main "target group" and recreate its dynamic - a chance for somewhat accidental meetings and clashes of perspectives. The research community can become a part of this discussion.

In "Slots of Trouble, Slots of Fun", a text of unquestionable importance for the game history research, Erkki Huhtamo criticizes the current findings of the discipline, concentrated on "amassing and organizing data" and trapped in the "chronicle era", as he puts it, referring probably to Nietzsche's critique of "antiquarian history" (2005). He is certainly partly right in connecting this state of things with the fan and insider perspectives that dominate in the writing about game history. His overall diagnosis is nonetheless very harsh: "None of the histories published so far develops a critical and analytic attitude towards its subject" (Huhtamo 2005, p. 6). I largely agree with Huhtamo; to put it simply, fans tend to make weak historians. And yet, their efforts deserve respect and appreciation. Moreover, their importance for the research practice cannot be overestimated. As Guins notes in the book I have already cited, even if Huhtamo is right about the lack of a critical attitude,

the 'collection era', exemplified by assorted documentation, archival, display, preservation, conservation, and restoration practices at cultural institutions such as libraries, museums, and universities, as well as itinerant exhibitions, private collections and information repositories produced by the gaming community-helps enable this very perspective by building (and most importantly, sustaining) historical collections for purposes of study, posterity, education, access, and cultural heritage. (Guins 2014, p. 25) 
As I have mentioned, it is the fans who largely support the material substance of heritage. Therefore, we should not replace one type of exclusion (of the academic perspective) with another (i.e., rejecting the fan narratives) but rather aim for a dialogue of equals. I do not intend to promote here the preservation of the original platform as the only appropriate way to archive games. In his incredibly pertinent article, significantly entitled It Is What It Is, Not What It Was, Henry Lowood reflects on the difficulties associated with collecting software and ponders the dilemmas related to the choice between the role of hardware and other issues relevant to the "authenticity of experience", noting that "authenticity" itself is a construct (as is the "authority" of the museum, one would like to add.) Lowood refers to this category as a "minefield", illustrating the resulting problems with a series of questions.

Whose lived experience counts as' authentic 'and how has it been documented? Is the best source a developer's design notes? The memory of someone who used the software when it was released? And video marketing? The researcher's self-reflexive use in a library or museum? If a game was designed for kids in 1985, do you have to find a kid to play it in 2050? In the case of software with a long history, such as Breakout or Microsoft Word, how do we account for the fact that the software was used on a variety of platforms-do repositories have to account for all of them? For example, does the playing of DOOM 'death match' require peer-to-peer networking on a local area network, a mouse-and-keyboard control configuration and a CRT display? There are documented cases of different configurations of hardware: track-balls, hacks that enabled multiplayer via TCPIP, monitors of various shapes and sizes, and so on. Which differences matter? (Lowood 2016)

The case study presented in this article is thus not concerned with naive fantasies of recreating "authentic" or "real" experience. "Authenticity" is not a response to the museum's "authority", whose critique I have mentioned earlier. Both categories mask an underlying entanglement of relations between actors with different levels of agency. "It is what it is", as Lowood noted, collections will be nothing more than they are, and there is no perfect strategy for their creation and use. Therefore, I do not mean to fetishize the preservation of the original hardware platforms-according to Lowood, the visitors sometimes even prefer the emulators. There are also several examples of successful attempts to "revive" old games in new contexts where the question of hardware is secondary at most (as in the case of The Museum of Digital Art and Entertainment and its project to reactivate Habitat, a multiplayer online game from 1986: neohabitat.org). Even if (though this may be a sign of a local perspective) the preservation of hardware is not insignificant and-considering the scant interest of the traditional institutions - the creation of such collections by the fans appears as one of the key ways to achieve this goal, it is only one of the possible proposals. What is crucial is the creation of platforms around which-following the new paradigm of thinking about museums-there could sprout lively, diverse and inclusive communities allowing for a dialogue about technology, its uses and history. It is crucial to keep these questions in social circulation, outside the walls of research and heritage institutions.

Fan efforts are a chance to preserve objects and, as I have tried to prove, animate activity around them, an opportunity to recreate, or simply to discuss the social aspects of the dispositif that accompanies games. This, naturally, poses certain problems, as always in the case of living social fabric, but also creates a platform for negotiation. After all, objects already brought by the fans to the museums, sometimes literally "from the street", could be well supplemented with others, delivered from the research units. Consequently, entering a relation with the fans seems not only worth considering but simply inevitable.

Funding: This publication was co-financed with a subsidy granted by the Ministry of Science and Higher Education to the Institute of Humanities (SWPS University of Social Sciences and Humanities) for maintaining and developing the didactic and research potential.

Acknowledgments: The author would like to thank four anonymous reviewers for their insightful and helpful comments and suggestions. 
Conflicts of Interest: The author declares no conflict of interest.

\section{References}

Bal, Mieke. 1996. Discourse of the Museum. In Thinking about Exhibitions. Edited by Reesa Greenberg, Bruce W. Ferguson and Sandy Nairne. Abingdon: Routledge.

Bennett, Tony. 1998. Culture. A Reformer's Science. Thousand Oaks: SAGE Publications.

DeLeon, Christopher. 2014. Arcade-Style Game Design-Pinball's Connection to Coin-Op Videogames. Kinephanos, 43-57. Available online: https://www.kinephanos.ca/2014/arcade-style/ (accessed on 26 February 2020).

de Kosnik, Abigail. 2016. Rogue Archives. In Digital Cultural Memory and Media Fandom. Cambridge: MIT Press. deWinter, Jennifer, and Carly A. Kocurek. 2017. Repacking My Library. In Fans and Videogames. Histories, Fandom, Archives. Edited by Melanie Swalwell, Helen Stuckey and Angela Ndalianis. Abingdon: Routledge.

Ellis, Carolyn, Tony E. Adams, and Arthur P. Bochner. 2011. Autoethnography: An Overview, Forum: Qualitative. Social Research 12: 37-49. Available online: http://www.qualitative-research.net/index.php/fqs/article/view/ 1589/3095 (accessed on 26 February 2020).

Falk, John H., and Lynn D. Dierking. 1992. The Museum Experience. Washington: Whalesback Books.

Filiciak, Miroslaw. 2018. "Generation Channel 36": Pirated VHS Tapes and Remembering the Polish People's Republic in the Age of P2P Networks. In Materializing Memories. Dispositifs, Generations, Amateurs. Edited by Susan Aasman, Andreas Fickers and Joseph Wachelder. London: Bloomsbury Academic.

Foucault, Michel. 1980. The Confession of the Flesh [Interview, 1977]. In Power/Knowledge: Selected Interviews and Other Writings. Edited by Colin Gordon. New York: Pantheon Books.

Golding, Dan, and Lina van Deventer. 2016. Game Changers. From Minecraft to Misogyny. Melbourne: Affirm Press. Guins, Raiford. 2014. Game After: A Cultural Study of Video Game Afterlife. Cambridge: MIT Press.

Hargittai, Eszter, and Christian Sandvig, eds. 2015. Digital Research Confidential: The Secrets of Studying Behavior Online. Cambridge: MIT Press.

Harrison, Rodney. 2015. Beyond 'Natural' and 'Cultural' Heritage: Toward an Ontological Politics of Heritage in the Age of Anthropocene. Heritage E Society 8: 24-42.

Heesen, Anke Te. 2012. Theorien des Museums zur Einführung. Hamburg: Junius.

Hölling, Hanna B. 2017. Paik's Virtual Archive: Time, Change, and Materiality in Media Art. Berkeley: University of California Press.

Huhtamo, Erkki. 2005. Slots of Fun, Slots of Trouble. Toward An Archaeology of Electronic Gaming. In Handbook of Computer Games Studies. Edited by Joost Raessens and Jeffrey Goldstein. Cambridge: MIT Press.

Huhtamo, Erkki, and Jussi Parikka, eds. 2011. Media Archaeology: Approaches, Applications, and Implications. Berkeley: University of California Press.

Kirschenbaum, Matthew, Erika L. Farr, Kari M. Kraus, Naomi Nelson, Catherine Stollar Peters, Gabriela Redwine, and Doug Reside. 2009. Digital Materiality: Preserving Access to Computers as Complete Environments. Available online: https://mkirschenbaum.files.wordpress.com/2009/10/digitalmaterialityipres2009.pdf (accessed on 26 February 2020).

Lowood, Henry. 2016. It Is What It Is, Not What It Was. Available online: http://refractory.unimelb.edu.au/2016/ 08/30/henry-lowood/ (accessed on 26 February 2020).

Montfort, Nick, and Ian Bogost. 2009. Racing the Beam. Cambridge: MIT Press.

Mortensen, Torill E. 2018. Anger, Fear, and Games: The Long Event of \#GamerGate. Games and Culture 13: 787-806.

Nagle, Angela. 2017. Kill All Normies: Online Culture Wars from 4chan and Tumblr to Trump and the Alt-Right. Alresford: Zero Books.

Navarro-Remesal, Victor. 2017. Museums of Failure: Fans as Curators of Bad, Unreleased, or "Flopped" Games. In Fans and Videogames. Histories, Fandom, Archives. Edited by Melanie Swalwell, Helen Stuckey and Angela Ndalianis. Abingdon: Routledge.

Parikka, Jussi. 2010. What Is New Materialism. Available online: https://jussiparikka.net/2010/06/23/what-is-newmaterialism-opening-words-from-the-event (accessed on 26 February 2020).

Saukko, Paula. 2005. Methodologies for Cultural and Studies: An integrative approach. In The SAGE Handbook of Qualitative Research. Thousand Oaks: Sage Publications. 
Suominen, Jaakko. 2016. How to Present the History of Digital Games: Enthusiast, Emancipatory, Genealogical, and Pathological Approaches. Games and Culture 12: 544-62. [CrossRef]

Turkle, Sherry. 2007. Evocative Objects. Cambridge: MIT Press.

Yúdice, George. 2003. The Expediency of Culture: Uses of Culture in the Global Era. Durham: Duke University Press.

(C) 2020 by the author. Licensee MDPI, Basel, Switzerland. This article is an open access article distributed under the terms and conditions of the Creative Commons Attribution (CC BY) license (http://creativecommons.org/licenses/by/4.0/). 